$$
\begin{aligned}
& \text { DOE/EW//2823-TT } \\
& \text { RECENGE } \\
& \text { APR } 041936 \\
& \text { OSTI }
\end{aligned}
$$

\title{
TIME DOMAIN ELECTROMAGNETIC METAL DETECTORS
}

\author{
By: Pieter Hoekstra
}

Blackhawk Geosciences

301 Commercial Road, Suite B

Golden, Colorado 80401

(303) $278-8700$

MASTER

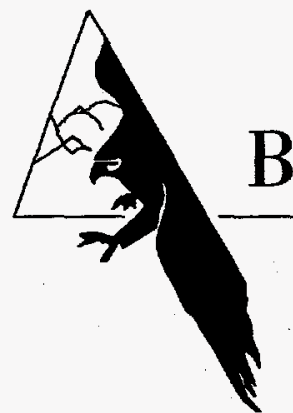

BLACKHAWK GEOSCIENCES

DISTRBBUTON OF THS DOCUMENT IS UALHATED

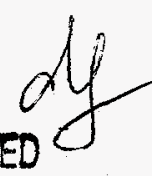




\section{DISCLAIMER}

This report was prepared as an account of work sponsored by an agency of the United States Government. Neither the United States Government nor any agency thereof, nor any of their employees, make any warranty, express or implied, or assumes any legal liability or responsibility for the accuracy, completeness, or usefulness of any information, apparatus, product, or process disclosed, or represents that its use would not infringe privately owned rights. Reference herein to any specific commercial product, process, or service by trade name, trademark, manufacturer, or otherwise does not necessarily constitute or imply its endorsement, recommendation, or favoring by the United States Government or any agency thereof. The views and opinions of authors expressed herein do not necessarily state or reflect those of the United States Government or any agency thereof. 


\section{DISCLAIMER}

Portions of this document may be illegible in electronic image products. Images are produced from the best available original document. 


\title{
TIME DOMAIN ELECTROMAGNETIC METAL DETECTORS
}

\author{
Pieter Hoekstra \\ Blackhawk Geosciences \\ 301 Commercial Road, Suite B \\ Golden, Colorado 80401 \\ (303) $278-8700$
}

\section{INTRODUCTION}

Two preceding presentations in this conference deal with time domain electromagnetic (TDEM) systems for buried metal detection: a presentation by J. McNeill of Geonics, Ltd.; and one by Peter Kaczkowski of the University of Washington. To avoid duplication this presentation will focus on illustrating by case histories the range of applications and limitations undoubtedly stressed by the previous presenters. Advantages claimed for TDEM metal detectors are:

1. Independence of instrument response (Geonics EM61) to surrounding soil and rock type.

2. Simple anomaly shape.

3. Mitigation of interference by ambient electromagnetic noise.

4. Responsive to both ferrous and non-ferrous metallic targets.

The data in all case histories to be presented were acquired with the Geonics EM61 TDEM system.

\section{CASE HISTORY}

\section{Case History 1: Test Bed Site on Molokai, Hawaii}

Ogden Environmental Services Co. prepared a test bed with inert ordnance to evaluate the capabilities of various subcontractors to detect ordnance buried over volcanic terrain typical of the Hawaiian Islands with an eye to the large remediation efforts forthcoming for Kaho'olawe. Volcanic terrain presents two unique difficulties to buried metal detection. These are:

1. Large variation in magnetic susceptibility can cause high noise in magnetic sensor.

2. The often rough surface can cause high noise in sensors sensitive to change in height above surface.

Figure 1 shows the color contour map of the electromotive force (EMF) measured by the Geonics EM61. The data were acquired at 3 foot line spacing, and with recording intervals along the lines of about 0.6 feet. Superimposed on Figure 1 are the UXO targets seeded in the test bed, and Table 1 contains information about the ordnance and depth of burial. Also listed in Table 1 is the signal/noise ratio of the each anomaly. The site was at the perimeter of a Navy bombing range and anomalies found in addition to the seeded targets are exploded ordnance waste. This case history illustrates critical characteristics of the Geonics EM61 TDEM metal detector. They are:

- All seeded targets were detected with a signal-to-noise ratio in excess of 2.1 and or high as 11.3.

- The anomalies over isolated targets are simple bell shaped. This greatly facilitates development of automated picking algorithms and neural network approaches.

\section{Case History 2: Fort Monroe, Virginia}

Fort Monroe dates as a military facility from 1609 , and the dominant objective was to locate pre-Civil War cannon balls and ordnance of a later origin.

Figure 2 shows a color contour map of the EMF measured with the Geonics EM61 over a section of Fort Monroe. The data were acquired with the EM61 in a wheel mode at 5 foot line spacing and about 0.6 feet recording interval along the line. This work was performed by Blackhawk Geosciences as a subcontractor to Parsons Engineering. For this work, the northern and easting of the anomaly center was picked by an automatic picking routine with a cursor on the computer screen. Again, this case history illustrates several of the advantages of a TDEM sensor.

1. The response of the surrounding soil is very low, showing the near independence of the sensor to soil and rock types.

2. The buried utility is identified by its linear trend.

3. Simple anomaly shape of isolated targets.

4. Some anomalies were dug up and some were ferrous (cannon balls), others were non-ferrous (a British riding stirrup).

\section{Case History 3: USDOE - Rocky Flats Plant}

This case history is not related to UXO detection, but was selected to illustrate the mitigation of instrument response to ambient electromagnetic noise. The objective of this survey 
was to locate waste in metallic containers buried in a trench that mainly contains ash. For several years, we were unsuccessful in locating metallic targets at this location with ground penetrating radar, magnetic, and frequency domain electromagnetic sensors. The reasons for this was that the trench ran near parallel and under a high voltage power line causing high noise in magnetic and frequency domain (Geonics EM31) sensors. The area was re-surveyed with the Geonics EM61 TDEM system, and the response was virtually not influenced by ambient noise.

Figure 3 compares contour maps of the EMF measured with the Geonics EM61 and total magnetic field measured with magnetic sensors. The EM61 detector allows clear anomaly detection under the high voltage power lines.

The ability to effectively perform surveys in high ambient noise environments is an important one. Urban developments have encroached on former defense sites, e.g., at Fort Monroe, surveys were performed between base housing with overhead and underground 60-cycle power lines, and cleanup other bases will require also working in high ambient noise environments.

\section{SUMMARY}

The TDEM metal detector has proven effective for detection of buried metallic targets. The advantages previously listed for the instruments have clearly been realized in the field. The present limitations of this technology are:

- Discrimination capabilities in terms of type of ordnance, and depth of burial is limited.

- Ability of resolving targets with small metallic ambient needs to be improved.

The direction for making improvements in the technology are evident (some are discussed in a previous paper by $\mathrm{J}$. McNeill) and within present capabilities. Adding additional time gates will assist discrimination, and so will developments of neural network approaches (Lavely this conference). 


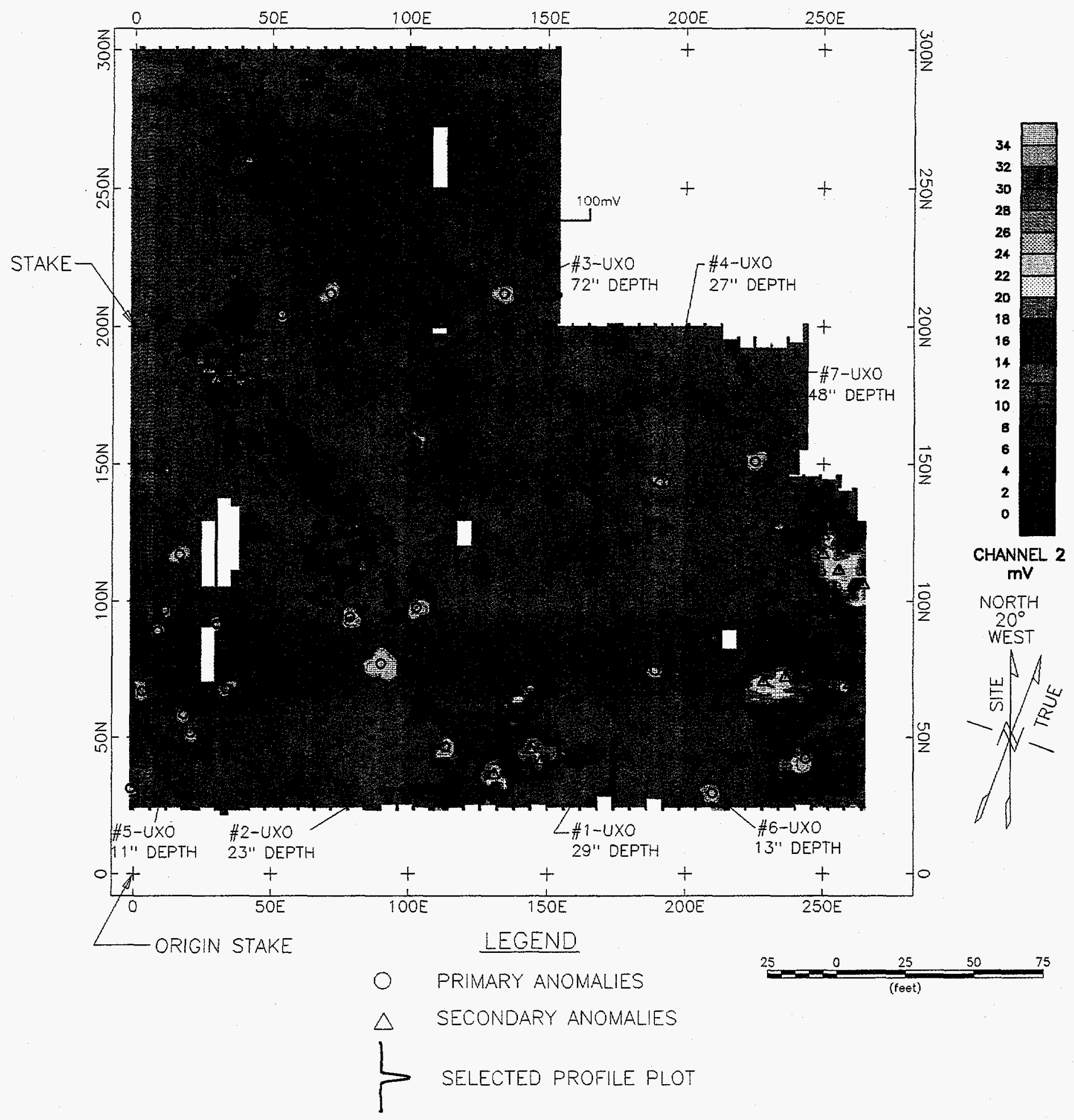

Figure 1.

Contour map of electromotive force measurement with

Geonics EM61 (channel 2) over test bed of Ogden Environmental, Inc. on Molokai, HI. All seeded anomalies were detected, and the numbering of each anomaly is superimposed on the figure. Table 1 provides specifics on each anomaly. 
Table 1

Type, depth of burial, location, and signal to noise ratio with Geonics EM61 (channel 2) of seeded anomalies in Ogden Environmental, Inc. on Molokai, Hawaii

\begin{tabular}{|l|c|c|c|c|c|}
\hline UXO DESCRIPTION & DEPTH & EASTING & NORTHING & $\underline{m V}$ & $\underline{\text { S/NRATIO }}$ \\
\hline & & & & & \\
\hline \#1 - MK-1 ROCKET WH & $29^{\prime \prime}$ & 188.9 & 74.6 & 81.4 & 7.4 \\
\hline & & & & & \\
\hline \#2 MK-76 PRACT. BOMB & $23^{\prime \prime}$ & 113.2 & 46.6 & 31.2 & 2.7 \\
\hline \#3 - 5" RKT. WH & & & & & \\
\hline & $72^{\prime \prime}$ & 134.2 & 212.0 & 73.4 & 8.0 \\
\hline \#5 - 2.75" RKT. WH & $27^{\prime \prime}$ & 190.5 & 143.3 & 23.8 & 2.1 \\
\hline & & & & & \\
\hline \#6 - 81mm MORTAR & $13^{\prime \prime}$ & 209.8 & 29.7 & 59.1 & 4.9 \\
\hline & & & & & \\
\hline \#7 - 105mm ARTILLERY & $48^{\prime \prime}$ & 225.1 & 150.9 & 129.2 & 11.3 \\
\hline
\end{tabular}



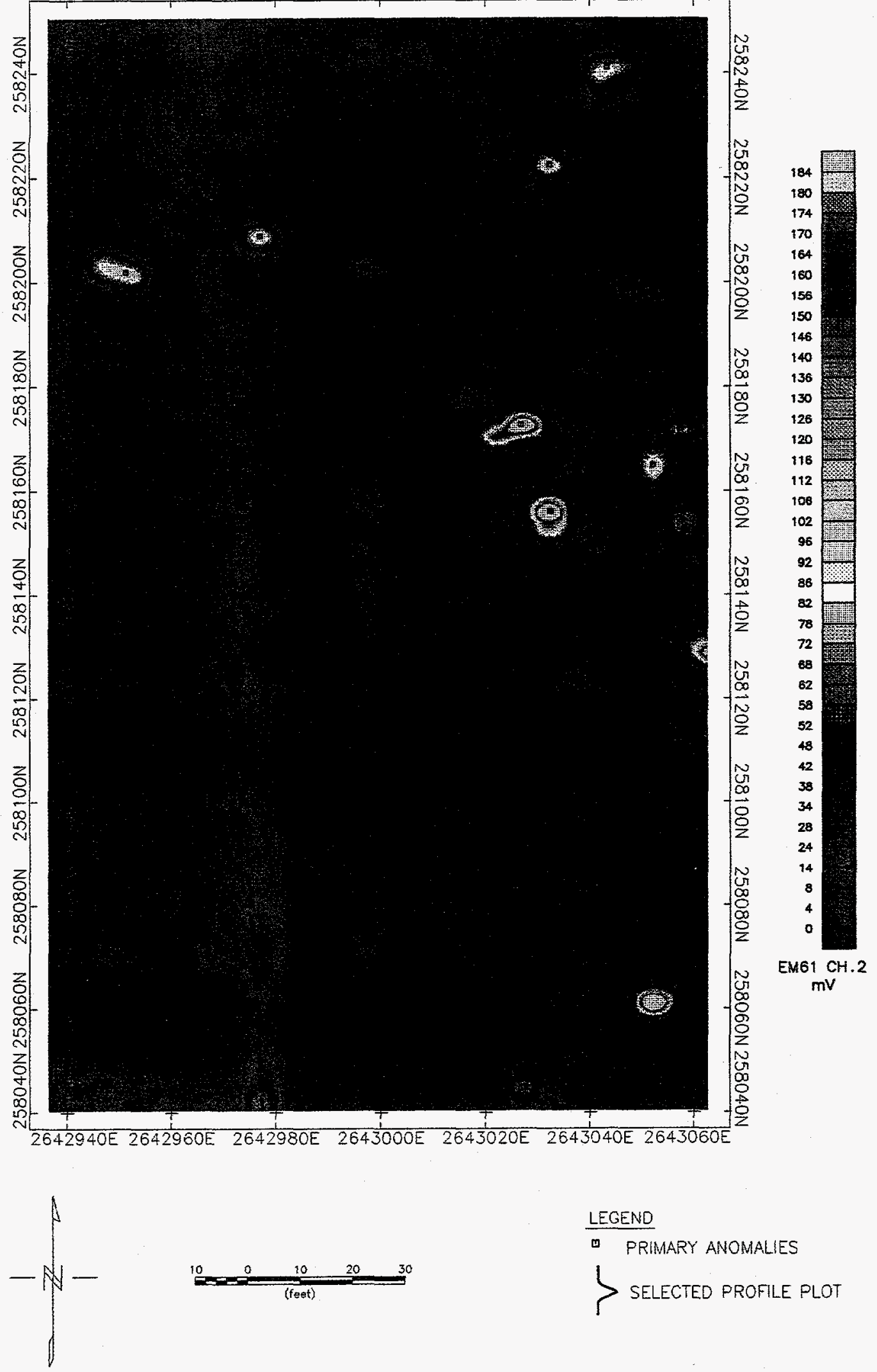

LEGEND

PRIMARY ANOMALIES

SELECTED PROFILE PLOT

Figure 2.

Contour map of the electromotive force measured with the Geonics EM61 (channel 2) over a section in Fort Monroe, VA. 


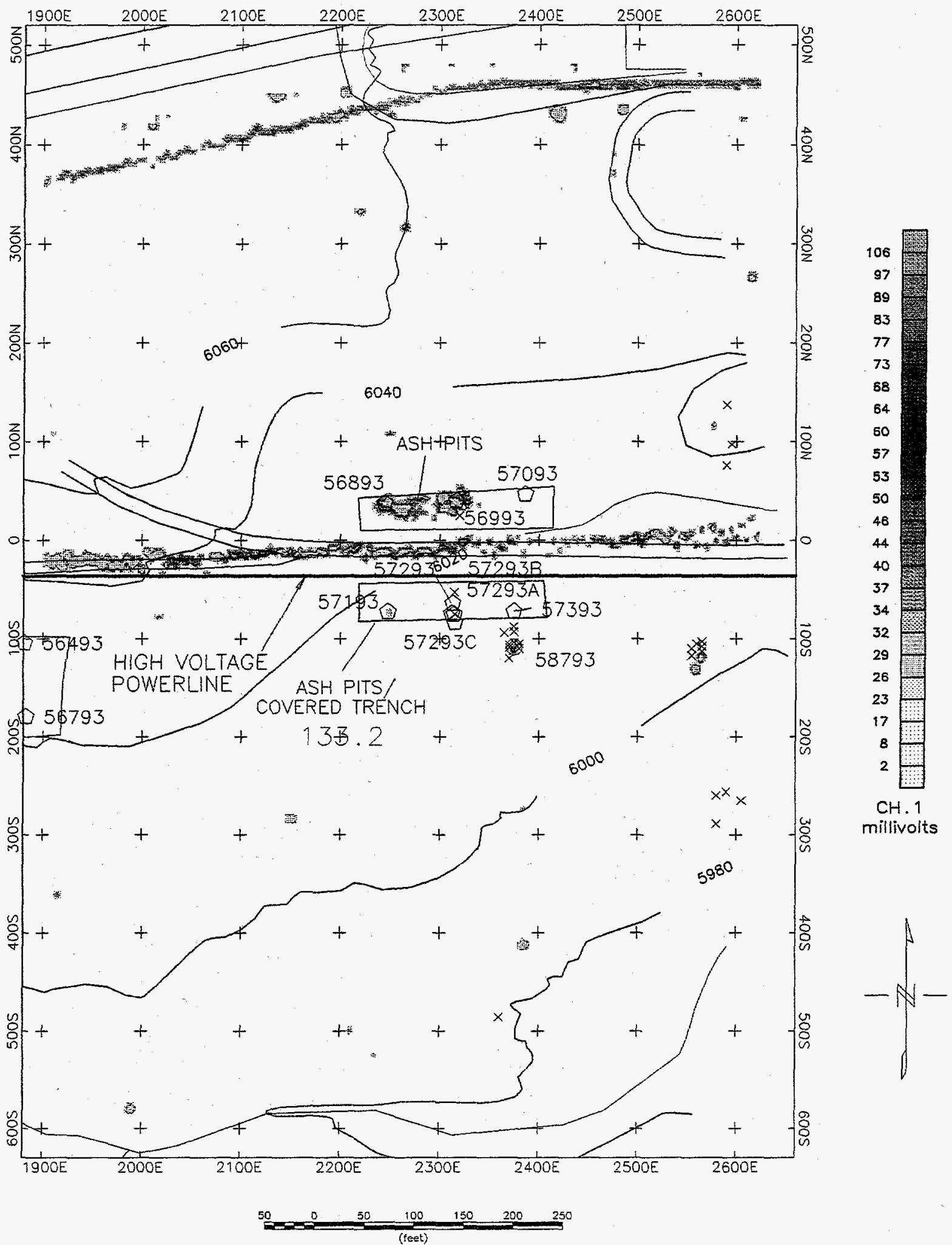

Figure $3 \mathrm{~A}$.

Contour map of the electromotive force measured with the Geonics EM61 (channel 2) over ash pits at Rocky Flats, CO. The location of a high voltage power line is superimposed on the map. 


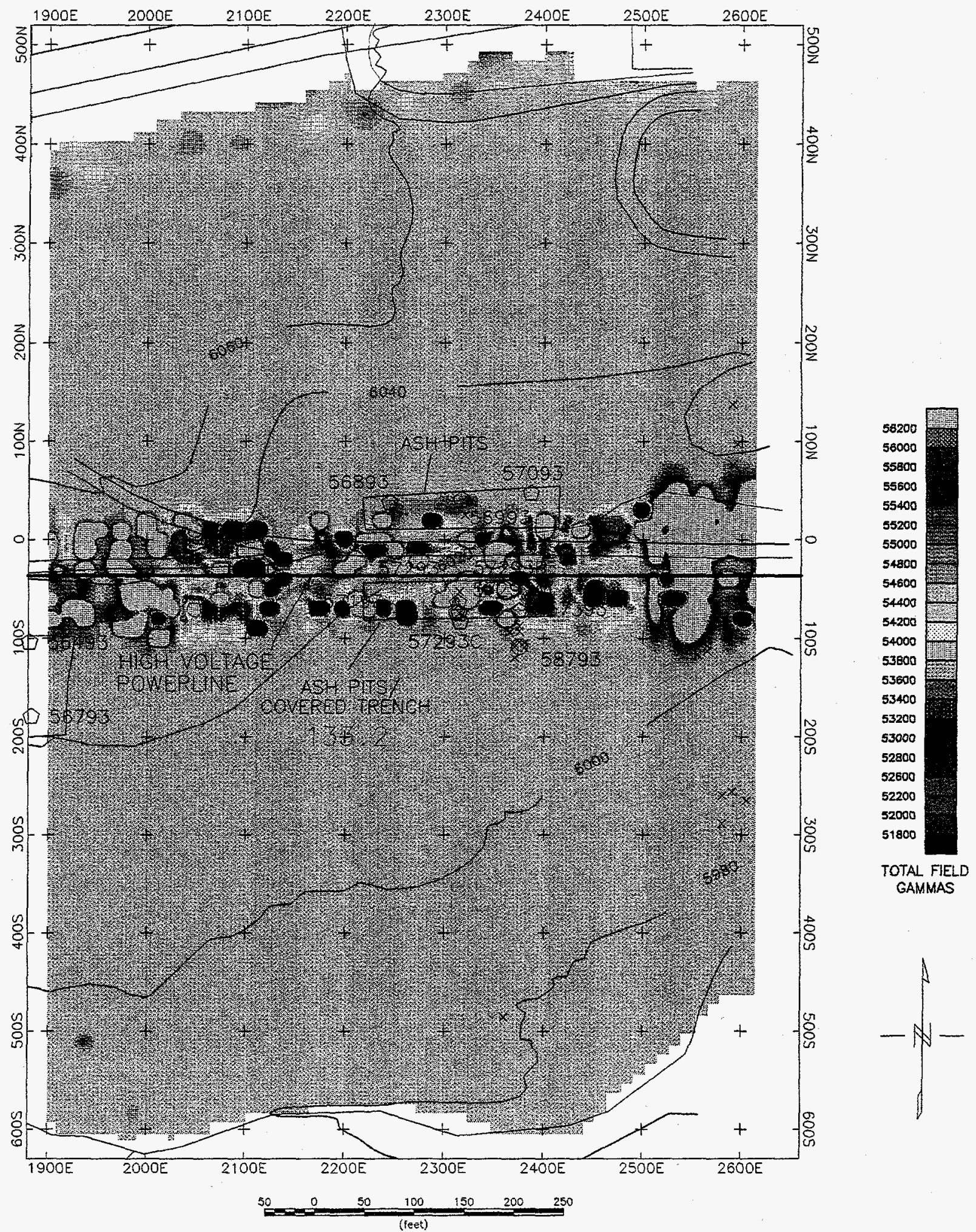

Figure 3B.

Contour map of total magnetic field measurement with Syntrex ENVI-MAG proton precession magnetometer. 